\title{
Toxic Gas Sewage System
}

\author{
D.Saranya, P.Gokulathilagan, Amalshaju, Immanuel.G
}

\begin{abstract}
The robots area unit is currently used for various functions that transform the work of humans. The Wireless Human Action Mechanism can be filed in a new generation of artificial intelligence, while researching the area unit commands, so that these robots can improve their maneuverability and effectiveness in those areas. The gas detection work mechanism may be a new generation of robots that address the problems of the sewer system and make it easier to detect hazardous gas in the battlefield, the chemical industry, and coal mining. Wirelessly controlled robotics vehicles are coupled with two sensors and a camera, which allows you to capture careful video of the environment in one setting. Used in the GSM robot, this helps to send the details around the system. This type of robot is controlled by a remote controller, which facilitates the robot's movement across terrain.
\end{abstract}

Index Terms - RF controller, sensors, GSM, Arduino Uno.

\section{INTRODUCTION}

Human lives square measure additional necessary than something within the world. individuals lose their lives main because of the numerous accidents occur because of negligence and while not following safety rules. Sometimes, the accidents square measure because of the quality of living of individuals. many folks in Indian square measure below poverty level and that they adopt substandard work to guide their day to day life. This makes them ignore the security measures. quite again and again they work close to the emptying place wherever there square measure several manholes. Lack of standby employee outside the hole for communication for emergency purpose conjointly ends up in accidents. emptying cleanup individuals don't seem to be conscious of risk of unforeseen attack of toxic gas; if the gases square measure odorless they'll be exposed thereto for a protracted time which can cause serious health issues. Gases like $\mathrm{CH} 4$ (methane) square measure odorless that with concentration on top of 350ppm cause confusion and fainting, on top of it'll sure as shooting kill individual. every gas has its own physical and chemical properties, that create them tough to investigate with none instrument. cyan genetic gases gift in numerous levels counting on the concentration and density of it.. For H2S (hydrogen sulfide) gas is heavier and it's gift at the lower surface, whereas the $\mathrm{CH} 4$ is bit heavier than sulphide. Thence it says on top of the $\mathrm{H} 2 \mathrm{~S}$ : the $\mathrm{CH} 4$ gas is lighter than the on top of mentioned gases and stays close to the waste man hole. They're several gas sleuthing sensors mentioned within the Literature. The air particles diffuse through the chemistry sensors to the conductor and with chemicals alter or reduced

Revised Manuscript Received on December 30, 2019.

* Correspondence Author

D.Saranya*, Assistant Professor, Department of EEE, Aarupadai Veedu Instituite of Technology, Vinayaka Missions Research Foundation, Chennai, India.

P.Gokulathilagan, AmalShaju, Immanuel, UG Student, Department of Mechatronics. AarupadaiVeedu Institute of Technology. relying upon the property of gas. The methane is change once it passes the conductor and warmth the sensors. the warmth is directly proportional to the number of gas as gift there. though' instruments square measure on the market in marketplace for sleuthing the cyan genetic gases however they're not reasonable by poor emptying cleaner who's monthly earning is a smaller amount than the detectors on the market.

An HMI has been developed in Lab view, where a person can manage their movements using the keyboard keys, such as the temperature measurement, the presence of toxic gases, and the presence of a number of environmental factors. The presence and live video streaming of that particular region can also be transmitted wirelessly [1]. Plume-tracing cellular robots are available to detect emissions from dangerous sources, such as early-stage fires, poison gasoline and ammunition, without threatening human existence throughout the detection and source localization system [2]. A rule-based supervisory approach for integrating robots to localize a smell source in an easy metropolitan environment is proposed, with a complex city environment and an indoor office environment respectively [3].The system presented will display the pulse price of a individual the use of a pulse oximetry sensor, the methane concentration and the atmospheric oxygen awareness and supply alert to employee and exterior unit [4]

The preceding amassed expertise exhibits that giant variety of accidents in emptying at some stage in and as soon as a disaster. the most reasons being, gas accidents, explosive. It wishes the event of a system that may also facilitate minimize the human and material loss that happens during rescues operations in system. The sensors for discover the gas rectangular measure critical inside the automaton to be developed.

The idea of a wifi robot is in a position to help the rescue team entering a drainage system. This robot is used for descent quarter and rescue search operations. Go to the robotic drain and detect the amount of toxic fuel. To sending the statistics with help of GSM accumulate statistics from mobile.

The intention of the undertaking is to construct a robot that can be managed by means of an Avionic RCB6i (2.4 GHz 6ch, transmitter with receiver) interfaced with arduino uno. The commands are assigned to the robot from the RF job in accordance with those commands. The DC motor is additionally integrated with the arduino for their management and operation as commanded from the RF.

\section{PROPOSED SYSTEM}

Toxic gases are gases that are damaging to residing things. They can without problems construct up in confined working spaces when the manufacturing system makes use of noxious gases. It may also end result in the biological chemical 
breakdown of a substance that is being stored in tank sewage. Sewer gas is a complicated combination of toxic and un hazardous gases produced and accumulated in sewage systems by using the decomposition of natural household or industrial wastes, ordinary aspects of sewage.

Methane is emitted during the handling and cure of municipal wastewater via the anaerobic decomposition of organic material. two These structures produce small amounts of methane emissions, but also massive amounts of bio solids that can end result in excessive prices of methane emissions.

The types of sewage toxic gas are

- Hydrogen sulfide(H2S)

- Nitrogen oxides(NO)

- Carbon monoxide(CO)

- Sulfur dioxide(SO2)

- Methane(CH4)

- Ammonia(NH3)

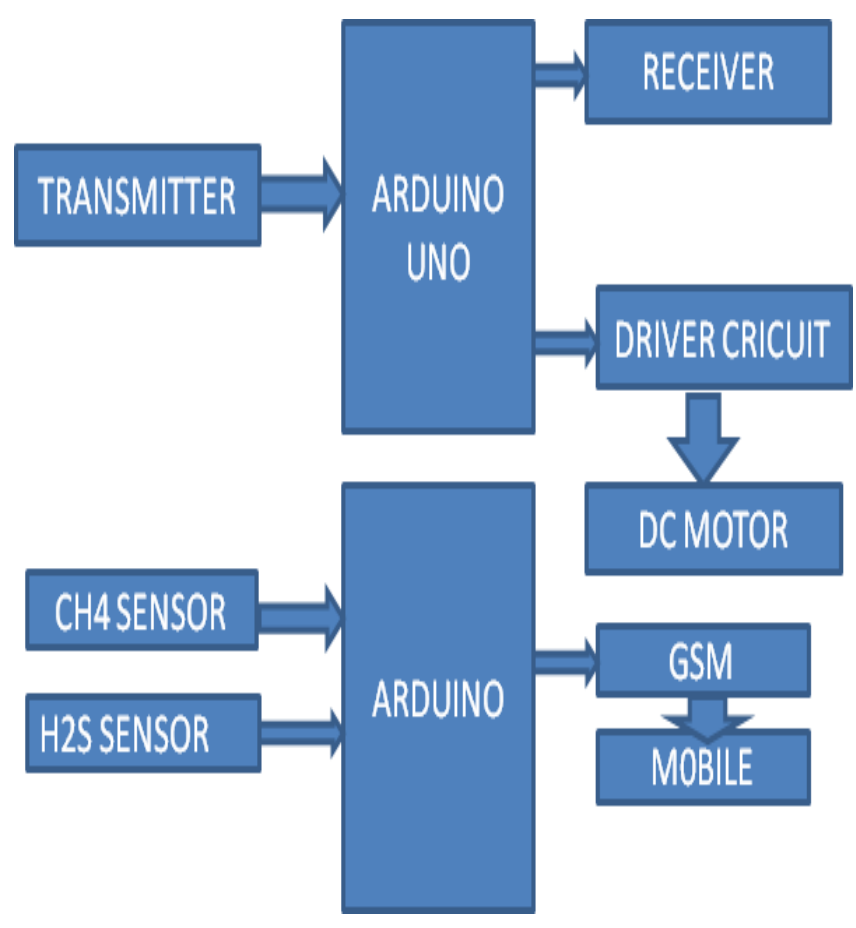

Fig. 1.Toxic gas sewage system block diagram

Methane is un hazardous when inhaled, however it can produce suffocation with the aid of lowering the concentration of oxygen inhaled. In most cases, dust explosions are first triggered by way of methane explosions. Hydrogen sulfide is denser than air. The combination of $\mathrm{H} 2 \mathrm{~S}$ and air will explode. Sulfur dioxide (SO2) and hydrogen sulfide are burned in oxygen with a blue flame to form water. Arduino is connected with receiver and driver circuit thus once the signal is transmitted from the transmitter it's received through the receiver then to the driving force circuit that runs the motor. Device is connected with the arduino, so once device detects it pass signal to arduino and to the GSM which is able to be received as text message.

A gas sensor is an electronic device that detects the presence of gases in an area.
- MQ 4 Gas Sensor Sensitive to Methane and CNG/Natural Gas

- MQ8 Gas Sensor Sensitive for Hydrogen Gas

Sensitive material of MQ-4 gas sensing element is $\mathrm{SnO}$, that with lower physical phenomenon in clean air. once the target flamable gas exist, The sensor's physical phenomenon is additional higher beside the gas concentration rising. MQ-4 gas sensing element has high sensitity to alkane series, additionally to fuel and alkane. The sensing element may be accustomed observe totally different flamable gas, particularly alkane series, it's with low price and appropriate for various application. Figure 2 shows the general sensing properties of MQ 4, the ratio of the resistance of the sensor to the ordinate (Ru / Row) is the concentration of the gases, the resistance of the

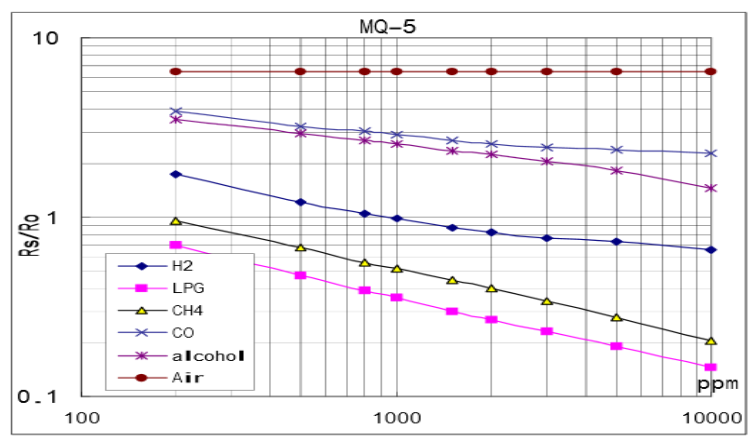

Fig. 2.Sensitive Characteristics of MQ4

different gases in the case of $\mathrm{R}$, and the resistance of the methane sensor in Rho is 1000 ppm. All tests are under standard test conditions. BS. The sensitivity to smoking is $8 \mathrm{~m} 3$ room lignite $10 \mathrm{pc}$ cigarettes, and the output is $200 \mathrm{ppm}$ methane.

Sensitive material of MQ-8 gas sensing element is $\mathrm{SnO}$, that with lower conduction in clean air. once chemical element gas exists, the sensor's conduction gets higher in conjunction with the gas concentration rising. MQ-8 gas sensing element has high sensitivity to chemical element gas, conjointly has anti-interference to different gases. This sensing element will find chemical element, particularly town gas. it's a form of low-priced sensing element for varieties of applications.

An RF or oftenness controlled golem while not employing a microcontroller may be a artificial intelligence vehicle that uses the oftenness wireless communication between the remote (the RF Transmitter) and therefore the actual golem (associated with the RF Receiver) and no microcontroller. we've got seen several form of golemic vehicles like line follower robot, bluetooth controlled golem, DTMF controlled golem, etc. however what build the RF contolled golem a distinctive project is it does't use progamming or a microcontroller to regulate the golem and therefore the vary between the transmitter (remote control) and reciver (robot) may be considerably larger than different types 


\begin{tabular}{|c|c|c|c|c|c|}
\hline Enable & In 1 & In 2 & In 3 & In 4 & $\begin{array}{c}\text { The state of dc } \\
\text { motor }\end{array}$ \\
\hline 0 & $\mathrm{X}$ & $\mathrm{X}$ & $\mathrm{X}$ & $\mathrm{x}$ & Stop \\
\hline 1 & 0 & 0 & 0 & 0 & brake \\
\hline 1 & 0 & 1 & 0 & 1 & Rotate clock wise \\
\hline 1 & 1 & 0 & 1 & 0 & $\begin{array}{c}\text { Rotate counter } \\
\text { clock wise }\end{array}$ \\
\hline 1 & 1 & 1 & 1 & 1 & brake \\
\hline
\end{tabular}

Fig. 3 Truth Table

Fig. 3 shows the truth table for giving input to the motor driver. The input to the motor driver IC or motor driver circuit is a low current signal. The circuit feature is to turn the low current signal into a high current signal. This excessive modern identification is then given to the motor. The movement of the wheels is governed by the driver IC positioned on the microcontroller. The robot's motors control the use of this driver's IC at 360 degrees of motion.

\section{RESULT AND DISCUSSION}

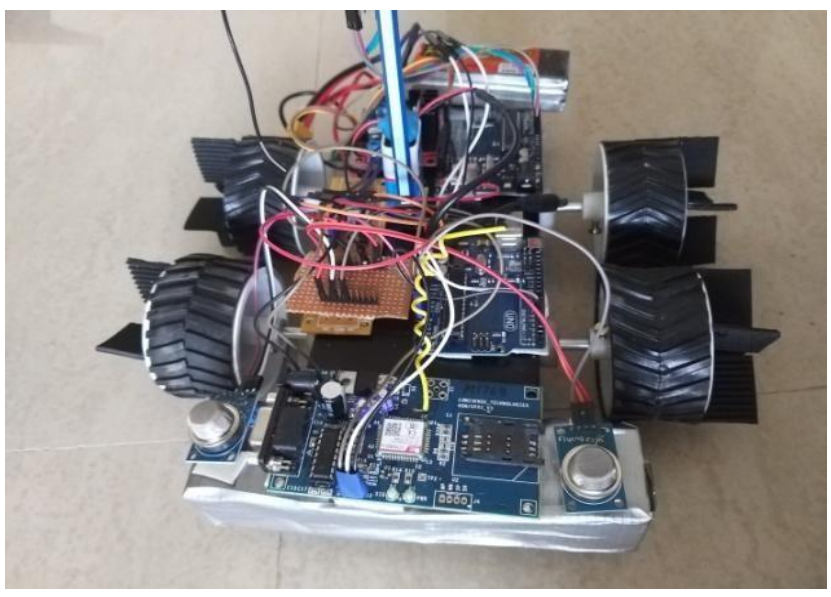

Fig. 4 Protomodule

The project prototype is shown in Fig 4. It can be used to detect toxic gases. We are monitoring 2 gases under this project, first is $\mathrm{CH} 4$, second is $\mathrm{H} 2 \mathrm{~S}$ by using two sensors MQ4 and MQ8. MQ4 is sensitive for methane gas and it is used to monitor methane gas. MQ8 is sensitive for hydrogen gas and it is used to monitor hydrogen gas. We have used GSM modem to send SMS to mobile phones. These values can later be seen using a mobile SM Sinbox. The inbox messages have shown below in Fig. 6. is has clearly shows that hydrolic acid detected and methane detected. So after receiving this alert message we can secure sewage works without affecting from the gases.
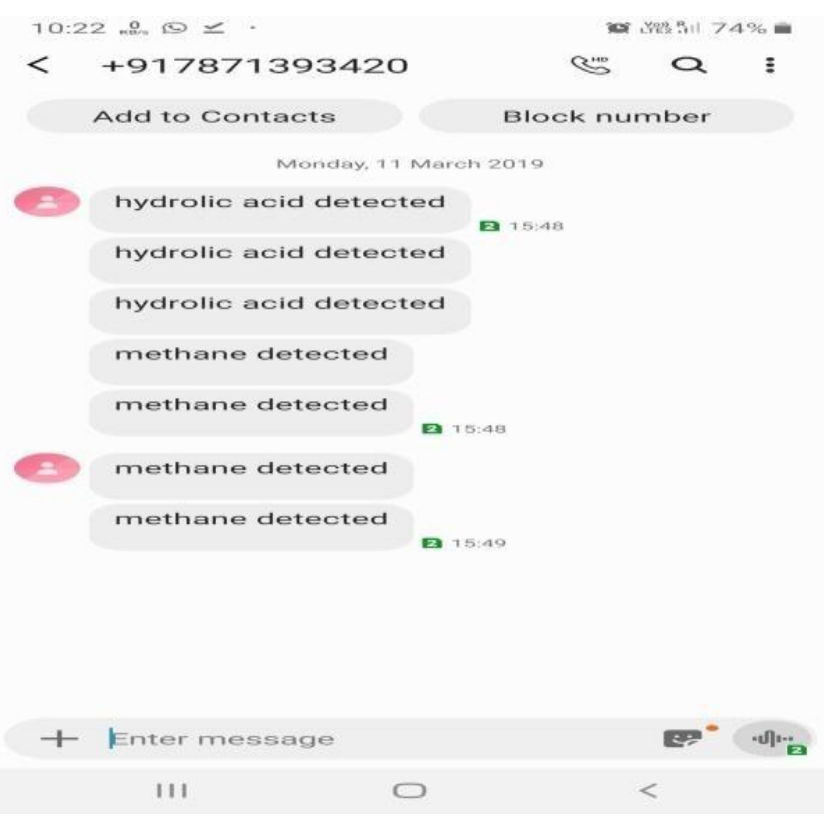

Fig. 5 Mobile Screen Shot

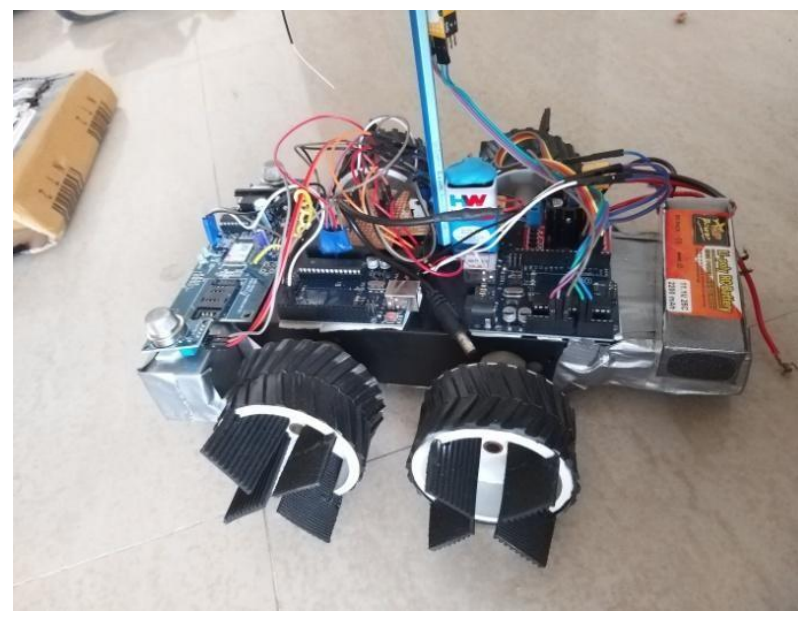

Fig. 6 Wheel Arrangement

Fig. 6 represents our proposed system design.where it incorporates four wheels which acts as a propeller as well as the general wheel.It has been designed such a way to adopt to the terrain surfaces and marine environments.

\section{CONCLUSION}

The development of science and technology can be a relentless development. New things and the new experiential area unit is imaginary. As technology grows daily, we can foresee the future as a reason for our tendency to empty every space.Sewage staff square measure benefited victimization this method. The mechanism enters into venturesome atmosphere and provides varied gas information.this paradigm system provides at ATmega 328p alert once venturesome gas level incrage.

ByusingMQ8(H2S),MQ4(CH4) sensors robot detect environment in the sewage by monitoring physical parameter and parameters aer observed using monitor status,log and display, and increase life safety of sewage workers 


\section{REFERENCES}

1. G 1. M. U. Shahzad, A. Q. Khan, S. M. R. Bukhari, A. Aslam and M. O. Zaib, "Wireless control robot using Xbee module with multiple sensor acknowledgment on HMI," 2017 International Symposium on Recent Advances in Electrical Engineering (RAEE), Islamabad, 2017, pp. 1-4.

2. Z. Liu and T. Lu, "Multiple robots plume-tracing in open space obstructed environments," 2009 IEEE International Conference on Robotics and Biomimetics (ROBIO), Guilin, 2009, pp. 2433-2439.

3. Z. Liu, "A supervisory approach for hazardous chemical source localization," 2013 IEEE International Conference on Mechatronics and Automation, Takamatsu, 2013, pp. 476-481.

4. N. G. Haswani and P. J. Deore, "Web-Based Realtime Underground Drainage or Sewage Monitoring System Using Wireless Sensor Networks," 2018 Fourth International Conference on Computing Communication Control and Automation (ICCUBEA), Pune, India, 2018, pp. 1-5.

5. Sabarish chakkath, S.Hariharan siddharth,B.Hemalatha;"mobile robot in coal mines disaster survalinace", IOSR jouranal of Engineering, volume-2,Issue10, october 2012

6. M.ThamrinN,RosmanR, andSATMEGA 8 AawiD,S"design and analysis of wireless controller panel using RFmoduel, for robot Natural Resources Canada, "Photovoltaic project analysis", Clean energy project analysis: retscreen engineering \& cases textbook, ISBN: 0-662-35672-1 Catalogue no.: M39-99/2003

7. V.K.Gobinath,S.Mohankumar.D.Veeramani D.Periyar selvan Hazardous gas detecting in coal mine robot

8. Dr.A.R.Karwankar,S.D.Mitragotri coal mine wireless robot for detection of hazardous gas.

9. Jayant Nivritti patil Advanced rescue and monitoring robot for coal mines.

10. Raguvaran.K,J.Thiyagarajan Raspberry PI based Global industrial process monitorning through wireless communication in international conference on robotics, automation, control and embedded systemRACE2015.

11. B.Thangalakshmi Energy Detection Based Spectrum Sensing In Cognitive Radio Network, International Journal of MC Square Scientific Research Vol.5, No.1 Nov 2013

\section{AUTHORS PROFILE}

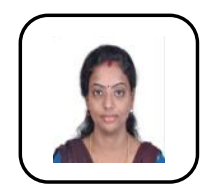

D.Saranya, She received her B.E in Electrical and Electronics Engineering (2007) from Thirumalai Engineering College and M.Tech in Power Electronics \& Drives (2014) from SRM University. She is research scholar in Department of Electrical Engineering, Vinayaka Missions Research Foundation. Her research interests include Renewable Energy System. She is currently a member of ISTE.

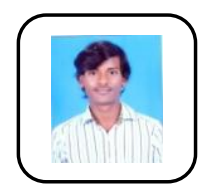

Gokulathilagan.P, UG Student. Department of MECHATRONICS. Aarupadai Veedu Institute of Technology. Chennai, India.

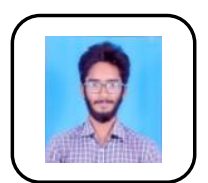

Amal Shaju, UG Student. Department of MECHATRONICS. Aarupadai Veedu Institute of Technology. Chennai, India.

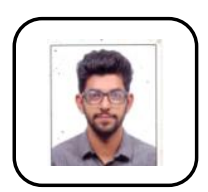

Immanuel.G, UG Student. Department of MECHATRONICS. Aarupadai Veedu Institute of Technology. Chennai, India. 